Fecha de recepción: abril 2019 Fecha de aceptación: octubre 2019 Versión final: diciembre 2019

\section{Holocausto y memoria en los tiempos de la globalización. Representaciones en el cine alemán}

\author{
María Elena Stella *
}

Resumen: Uno de los rasgos más notables de la época de la globalización, es, sin duda, el lugar central que ocupa la memoria en la cultura y la política de las sociedades occidentales. En efecto, a partir de las dos últimas décadas del siglo XX ha surgido una, casi obsesiva, preocupación por el pasado y, particularmente, por la memoria de los hechos histórico traumáticos. Tal fenómeno puede atribuirse, entre otras explicaciones, a que el mundo global, surgido del final de la guerra fría, a despecho de las optimistas primeras especulaciones, resultó un escenario violento, de genocidios, conflictos étnicos, nacionales y religiosos. De este modo, los principales protagonistas de la historia reciente pasaron a ser los emigrados, refugiados, genocidas, víctimas y victimarios y, tal como lo plantea Andreas Huyssen, el Holocausto se ha convertido en la matriz interpretativa universal de los hechos de violencia masiva (Huyssen, 2002, p. 13-22). Por otro lado, y relacionado con lo anterior, ha surgido un renovado interés por la memoria y la justicia sobre los criminales del nazismo. En este proceso, el cine ha tenido un papel relevante a través de un considerable número de películas de ficción y documentales que retomaron con asiduidad el tema, a partir la década 80, profusión que contrasta con la etapa anterior.

Según nuestra hipótesis, así como el Holocausto se convirtió en un tropos universal a la hora de explicar las grandes masacres y genocidios de la era actual, la cultura de la globalización volvió a la Shoá, formulando una fuerte crítica a toda la generación que siguió al evento -principales potencias, líderes políticos, instituciones- por haber sacrificado el pasado en función del presente y del futuro y haber consagrado el olvido, el silencio y la impunidad, durante varias décadas.

Dentro de este contexto de revisión del pasado nacionalsocialista y la preocupación por la justicia en relación con los perpetradores del que participa, notablemente, el cine, el presente trabajo se ocupará del filme Laberinto de mentiras (Ricciarelli, 2014), de sus vínculos con el contexto histórico de producción y los nuevos significados que construye en torno a aquellos hechos traumáticos sucedidos al promediar el siglo anterior. Nuestro enfoque considera al cine como fuente de la historia, en el sentido que da cuenta del contexto histórico en el que surge, sus preocupaciones, sus discursos (Ferró, 1995) y, por otra parte, apunta al análisis de sus representaciones para detenerse en los nuevos sentidos que le atribuye a ese pasado (Rosenstone, 1997).

Palabras clave: globalización - memoria - Holocausto - justicia - cine.

[Resúmenes en inglés y portugués en las páginas 93-94] 
${ }^{*}$ Historiadora (Facultad de Filosofía y Letras - UBA). Docente e investigadora de la Universidad de Buenos Aires. Profesora de Historia Económica y Social Argentina en la Facultad de Ciencias Económicas y de Introducción al Conocimiento de la Sociedad y el Estado en el Ciclo Básico Común de la Universidad de Buenos Aires; es, también, Profesora del Instituto de Enseñanza Superior del Profesorado No 1 Dra. Alicia Moreau de Justo. Doctoranda en Ciencias Sociales (UBA). Se ha dedicado a la investigación de la relación entre cine e historia, particularmente, de cine y genocidio. Ha dictado cursos en distintas universidades de la Argentina y participado en jornadas y congresos nacionales e internacionales. Ha publicado diversos artículos en revistas argentina y extranjeras y capítulos de libros en su área de especialidad.

\section{Introducción}

En la época de la globalización, la memoria del Holocausto ha experimentado por lo menos, tres derivas fundamentales. En primer lugar, su conversión en tropos universal o paradigma explicativo de las violaciones a los derechos humanos cometidas por los estados o con su anuencia en el último cuarto del siglo XX, fenómeno del que daba cuenta Andreas Huyssen $^{1}$ a la vez que señalaba los problemas que traía ese traslado, en ocasiones forzado, de conceptos y representaciones que, construidos para explicar el genocidio nazi, se aplicaban a acontecimientos muy distantes en tiempo y espacio del hecho original. No obstante, en muchos casos, se tradujo en un importante aporte a la comprensión de hechos de violencia masiva producidos a finales del siglo pasado ${ }^{2}$.

En segundo lugar, observamos la centralidad que adquieren los hechos histórico traumáticos en la cultura de la sociedad occidental, fenómeno del cual, la Shoá se convierte en su sinécdoque y se traduce en la musealización, la construcción de monumentos recordatorios, objeto de representaciones artísticas, literarias, tema de investigaciones de distintas disciplinas sociales y humanas. Por último, y relacionado con lo anterior, el proceso llega a derivar en la conversión de la memoria de la Shoá en una "religión civil", tal como lo señala, entre otros, el historiador Enzo Traverso', y que consiste en el pasaje de una 'memoria débil' a una 'memoria fuerte' en torno a la cual se construye un consenso universal que oculta los propios genocidios y violencias pasadas y presentes de los estados que se consagran a la nueva religión.

Sin perder de vista estas reflexiones, nuestro trabajo se centrará en dos momentos de la historia de la memoria de la Shoá: por un lado,la llamada "era Adenauer", desde la creación de la República Federal en 1949, hasta la sustanciación de los Juicios de Auschwitz en Frankfurt que culminan en 1965. Y, por otro lado, la Alemania de la segunda década del siglo XXI, momento en el cual se formula una fuerte crítica de la sociedad de los años cincuenta, en el sentido en que el escritor y documentalista Ralph Giordano llamó la "segunda culpa", es decir, el intento de eludir su responsabilidad en el reciente pasado violento, recurriendo a la negación, y a la amnistía de los crímenes que gran parte de la sociedad germana toleró, consintió o calló durante el periodo nacionalsocialista, es decir, la "primera culpa". 
La constelación de los dos momentos históricos, es posible percibirla a través del cine alemán de nuestros días, particularmente, este artículo se centrará en la película Laberinto de mentiras, también, titulada La conspiración del silencio, del realizador Giulio Ricciarelli (2014).

\section{Holocausto. Memoria y justicia: un proceso tardío, discontinuo y sinuoso}

La memoria de la Shoá recorrió un sendero complejo y discontinuo que la Historia ha intentado reconstruir, establecer sus etapas y contextualizar. La destrucción de los judíos de Europa por parte del nazismo fue considerada en la inmediata posguerra como un hecho que debía comprenderse dentro del marco de la Segunda Guerra Mundial. No concitó, por sí misma, un tratamiento particular ni estudios específicos. No se advirtió en el momento la extrema singularidad y la desmesura del acontecimiento. Como han señalado muchos historiadores, su inclusión en la conciencia de Occidente fue, por demás, tardía, ya que al suceso histórico siguió una etapa de represión del recuerdo en la que la voz de las víctimas fue desoída o subestimada durante dos décadas.

Por su parte, la justicia penal, estrechamente vinculada, aunque de manera compleja, con la memoria, se manifestó en una corriente de amnistías e impunidad que se extendió a finales de los años cincuenta.

Hasta la recuperación de la soberanía y la división de Alemania en dos naciones, la justicia transicional había estado a cargo de las potencias aliadas. Luego de los Juicios Principales de Nuremberg y los Secundarios, realizados entre 1945 y 1949, se instaló la idea de "cosa juzgada".

En la naciente República Federal Alemana, las tareas de la reconstrucción material e institucional del país soterraron el pasado reciente, la memoria y la justicia para con las víctimas y los victimarios. Por otra parte, como es sabido, la dinámica de la guerra fría apartó al suceso de una agenda, ahora más interesada en la lucha presente contra el enemigo comunista que comprometida en castigar a los criminales nazis. La drástica caída del número de denuncias, sumados a reiteradas leyes de amnistía y de prescripción, aún para casos graves, caracterizaron esta etapa de la Justicia retroactiva, o más bien, la casi ausencia de ella (Müller, 2006) 5

No obstante, antes de finalizar la década del cincuenta, tuvo lugar el retorno de lo reprimido, la anamnesis, una revuelta ético política contra la amnesia y la impunidad que reivindicó el deber de la memoria. Dos acontecimientos fundamentales impulsaron y fueron consecuencia, co-determinando, en forma dialéctica, un cambio de época en la que la búsqueda de la verdad y el castigo a los culpables recuperó un lugar en las preocupaciones de la Alemania de los tempranos sesenta. La captura de Adolf Eichmann en Argentina en 1960 y el posterior proceso judicial en Jerusalén en 1961, con amplia cobertura por parte de los medios masivos, impactó en la opinión pública mundial corriendo, en parte, el manto de olvido que se había tendido en torno al evento. De boca de uno de sus principales perpetradores, a través de las audiencias televisadas, se comenzó a tomar conciencia del genocidio. Dos años más tarde, otro acontecimiento del orden judicial va a develar más detalles del horror vivido: el juicio realizado en Frankfurt, desde 1963 a 1965, donde se 
juzgaron y condenaron a ejecutores materiales de hechos atroces cometidos en el campo de concentración y exterminio de Auschwitz

El fin de la guerra fría y el comienzo de la globalización presenció un desarrollo fenomenal de los estudios sobre el Holocausto, convirtiéndolo en un campo específico del saber dentro de la historiografía, acontecimiento, también, visitado por distintas disciplinas que lo abordaron desde múltiples perspectivas. La caída del Muro de Berlín, en 1989, tuvo fuertes consecuencias en el conocimiento histórico del Holocausto ya que permitió el acceso a importantes archivos hasta el momento ignorados en Occidente. Por otra parte, con la unificación de Alemania en 1990, la memoria de la Shoá cobró un valor especial en la tarea de fundar una identidad alemana, democrática, comprometida en saldar cuentas con el pasado totalitario y abocada a juzgar y castigar a los culpables que aún estaban impunes. En el plano de las representaciones audiovisuales, los estudiosos de la memoria de la Shoá coindicen en destacar la impronta de la serie televisiva "Holocausto" (EEUU, 1978) en la medida que el evento logró salir de los ámbitos académicos y penetrar en los hogares y en la conciencia de las familias en América y en Europa, fundamentalmente. Siete años más tarde, otro acontecimiento crucial resultó Shoá, (1985) del realizador francés Claude Lanzmann que vino a impulsar debates en las Ciencias Sociales, Humanidades y el Arte sobre los límites de las representaciones o la irrepresentabilidad del Holocausto. A partir de estas creaciones, la memoria de la Shoá, tuvo una progresión casi geométrica en los distintos campos del saber y del arte, muy, ostensiblemente, en el Cine, que contribuyeron a convertir, en nuestra época, a la Shoá en el trauma universal de Occidente.

\section{Laberinto de mentiras (Alemania, 2014)}

Im Labyrinth des Schweigens, su título original en alemán, es la ópera prima del actor y director italiano, Giulio Ricciarelli, co guionista del filme junto con Elisabeth Bartel. Su elenco se compone de Alexander Fehling, André Szymanski, Friederike Becht, Johannes Krisch, Johann von Bülow, Robert Hunger-Bühler, Hansi Jochmann y Lisa Martinek. Fotografía de Martin Langer y Roman Osin. Música de Sebastian Pille y Niki Reiser. Edición a cargo de Andrea Mertens. Duración 122 minutos.

La película aborda el espinoso tema de la elusión por parte de la gran mayoría de la sociedad alemana de su responsabilidad, por acción u omisión, en los crímenes horrendos del periodo nacionalsocialista. Comportamiento que mantuvo durante las dos décadas posteriores al fin de la guerra y que comienza a conmoverse a finales de los cincuenta, precisamente, el momento y las circunstancias representadas en la película de Ricciarelli. Dentro de la época referida, el director recorta un periodo de cinco años, desde que llega a la fiscalía de Frankfurt una denuncia hasta el inicio de las secesiones del Tribunal, en diciembre de 1963. Es la primera vez que el cine de ficción se hace cargo de tal acontecimiento ${ }^{7}$. Con una narrativa tradicional, sin demasiada innovación formal, el director construye un relato del pasado, que combina hechos reales, tomados del mundo histórico, con personajes y situaciones imaginarias, logrando un tratamiento serio y sobrio de un tema tan árido y esquivo a la cinematografía como lo es el universo de las denuncias, audiencias, archivos y testimonios. 
La reconstrucción de la época es impecable: la música, los artefactos cotidianos, las vestimentas, los diálogos, logran hacer revivir aquel momento de auge económico y conformismo de una sociedad que pretende alejarse de ese pasado que la interpela, embarcándose un futuro que promete progreso y bienestar material.

Ya, en la primer escena, se introduce el nudo de la cuestión, que es, precisamente, la impunidad y el manto de olvido tendido sobre los horrores del pasado reciente: corre el año 1958, un ex guardia del campo de Auschwitz es reconocido por, Simón, un sobreviviente del mismo. El criminal no solo está libre,sino que, además, es profesor de un colegio de niños. Esta representación constituye, a nuestro criterio, un importante logro del director, haber podido significar con imagen y sonido, una de las dimensiones más terribles del ausencia de justicia, poner frente a frente a la víctima, cuyo daño no ha sido reparado con el victimario, no solo, impune sino cumpliendo un rol de fuerte reconocimiento social como es la enseñanza de los niños, una verdadera paradoja.

La segunda escena, es la antítesis: la joven generación. Un novel abogado, que debe pagar su “derecho de piso' en la Fiscalía de Frankfurt y, confinado a resolver las infracciones de tránsito, sueña con un futuro vinculado a una gran misión. No subestima su tarea actual, pormenor que le parezca, sino por el contrario, se dedica con empeño a hacer respetar la ley y a castigar su incumplimiento, tesón que conservará, posteriormente, cuando tenga que acusar a los asesinos de Auschwitz. Este recurso le sirve al cineasta para dar cuenta de las características de estos fiscales -que en la realidad, fueron tres-: niños o adolescentes durante el nazismo, desvinculados del poder y con escasa experiencia en la Fiscalía pero con un fuerte compromiso con la justicia, la verdad y la ética. El protagonista, Johan Radmann, es un héroe inventado ${ }^{8}$. El personaje de ficción es un clásico héroe de película hollywoodense de los años cuarenta: joven, buen mozo, idealista, valiente, que, prácticamente, por azar entra en contacto con las denuncias de Auschwitz, cuya existencia, hasta el momento, ignoraba al igual que la mayoría de los empleados de la Fiscalía.

En un contexto en que los jóvenes desconocen el pasado y los mayores lo pretenden ocultar porque en alguna medida, estuvieron involucrados, se había instalado la idea de que "la democracia ya es un hecho en Alemania ¿para qué entonces hurgar en el pasado?", la denuncia contra los perpetradores es arrojada, literalmente, en el film - al cesto de la basura. Es el Fiscal Radmann quien lo rescata del olvido.

La reunión de fiscales, presidida por Fritz Bauer, es la oportunidad que elige el joven funcionario, cuando, desafiando a su inmediato superior, decide exponer, directamente, ante Bauer la denuncia recibida.

La representación del Fiscal General de Hesse que emerge de la película es la de una hombre realista, experimentado y, aunque, consciente de todos los obstáculos que se oponen al develamiento del pasado, está convencido de que no hay una verdadera democracia si Alemania no se hace cargo de sus crímenes.

Como en el juicio real, el rol del Fiscal General fue fundamental, pero, más bien, lo desempeñó detrás de la escena, dejando en 'primer plano" a su séquito de jóvenes fiscales en los que depositó su confianza y a los que brindó su apoyo.

Días más tarde, en la entrevista personal con Bauer, obtiene el espaldarazo que necesitaba. El Fiscal General, no solo lo va a apoyar en sus investigaciones, sino que lo coloca al frente de la misma, no sin antes, advertirle sobre las dificultades que deberá afrontar; por ejem- 
plo; "haber servido en el campo de Auschwitz, no es un delito para Alemania," y, por otra parte, "todos los crímenes prescribieron hace tres años".

A los obstáculos legales se suma un hecho, por demás, desalentador e inquietante, "el Funcionariado está repleto de antiguos nazis". La novedad, el suceso que se presenta como una posibilidad de comenzar a desmadejar la telaraña la impunidad es que ha llegado a la Fiscalía un listado, proporcionado por una víctima. Se trata de una planilla con los nombres de los miembros de la SS que se desempeñaron como directivos en el campo de Auschwitz. En su rasgo moderno de organizar el crimen a gran escala -la forma burocrática- el nazismo había dejado innumerables registros de su accionar delictivo que, finalmente, servirán de pruebas en su contra. Habría que sumar testimonios de sobrevivientes y lograr más pruebas de los delitos concretos. Por primera vez, se pondrían en relación los nombres de los ejecutores, las víctimas, los crímenes y la voluntad de investigarlos y castigarlos.

Comienza, así, un desfile de testigos que llega a la Fiscalía dando testimonio del horror vivido, ante el cual, los funcionarios pasan de la postura inicial de la ignorancia o las justificaciones tales como "eran soldados, cumplían órdenes" o bien "los vencedores escriben la historia, es todo una exageración" a la toma de conciencia del mayor crimen contra la humanidad de la época moderna.

Paripasu, se inician las citaciones a los integrantes las planillas del personal de Auschwitz, que lejos de cualquier actitud de arrepentimiento, niegan, justifican y amenazan, llegando uno de sus abogados a sostener el cínico argumento de que el proceso la selección que tenía lugar en el andén, a la entrada del lager, que decidía quienes se destinaban al trabajo forzado y quienes a la muerte, era un acto de piedad, que, en definitiva, había evitado a muchos su muerte inmediata en la cámara de gas.

En Laberinto de mentiras, la tramase bifurca. Tangencialmente, sigue el paradero de Josef Mengele, el, tristemente, célebre médico de Auschwitz, autor de siniestros experimentos con seres humanos, particularmente, con niños gemelos, como es el caso de las hijas de Simón, el personaje de la película.

El Fiscal Radmann está, especialmente, empeñado en llevar a la cárcel al "Ángel de la muerte" y obsesionado de tal manera que se le presenta en sus pesadillas. La persecución del criminal, al que considera, el emblema de Auschwitz, es la parte en que la película cobra un notable dinamismo, convirtiéndola en thriller policial. Finalmente, el fracaso en la captura de Mengele hace que Radmann caiga en la decepción y el abatimiento.

Sin embargo, hay otras razones de su frustración: en el trayecto de la pesquisa, el Fiscal descubre que la mayoría de sus allegados, amigos y colegas habían pertenecido a las SS durante todo el periodo nacionalsocialista. El caso más impactante es el de su propio padre, quien, lejos de la imagen del soldado que aún siendo opositor al nazismo, murió en el frente de guerra, en realidad, había sido un miembro activo del partido nacionalsocialista. De esta manera, el director da cuenta de una de las característica de los crímenes modernos,en este caso, del nazismo: la participación es tan masiva, los grados de complicidad son tan variados que hacen que la culpa se extienda sobre vastos sectores de la sociedad, llegando a la paradoja de que si la culpa es colectiva, nadie es culpable. Entonces ¿Dónde trazar la línea de los que deben ser juzgados y castigados y quienes, no? La cuantía de los victimarios, de las víctimas y de los delitos, así como su naturaleza radical, hacen que estos crímenes sean, como decía Hannah Arendt, imposibles de perdonar, pero a su 
vez, imposibles de castigar. Así, la película nos lleva a reflexionar sobre los obstáculos y dilemas con que se enfrenta la justicia transicional a la hora de juzgar los crímenes masivos. Abrumado por razones personales, materiales y legales, el Fiscal, como en los relatos clásicos, abandona el combate y se retira al ámbito privado, dónde ha recibido jugosas propuestas de personas interesadas en que se interrumpan sus investigaciones en la fiscalía. Sin embargo, muy pronto se imponen sus valores y su determinación de que Auschwitz no caiga en el olvido y vuelve al campo de batalla donde le aguardan excelentes noticias: ya hay fecha para los juicios de Auschwitz.

Llega el final, un día de diciembre de 1963, los magistrados lucen las tradicionales togas, la sala está dispuesta, hay entusiasmo y conciencia de que se va a protagonizar un hecho histórico. Se cierran las puertas de la Sala de Audiencias de Frankfurty la pantalla se oscurece porque ha finalizado Laberinto de mentiras, dando paso a la Historia (con mayúscula) que informa lo que, en el mundo histórico, siguió a esa escena.

\section{Algunas reflexiones finales}

Según Daniel Feierstein, el juicio penal no solo es un mecanismo formal destinado a la sentencia ya castigar a los perpetradores, sino que constituye un espacio de encuentro obligado entre victimarios y víctimas, en el que los hechos traumáticos pueden ser reconfigurados frente a todos los partícipes y donde se produce un juicio moral legitimado que asigna responsabilidades y contribuye a la conciencia social.(Feierstein, 2015) ${ }^{9}$. A partir de los Juicios de Auschwitz, en Frankfurt, los alemanes y mundo se enteraron de la verdad y la dimensión del horror vivido. Pudieron comprobarlo a través de los innumerables testimonios de las víctimas y demás testigos, de pruebas materiales irrefragables, documentos escritos e imágenes y, en algunos casos, de la declaración de los propios acusados. Ante las evidencias, se desmoronaron las versiones negadoras del suceso: no se trataba de la "historia contada por los vencedores", ni del relato exagerado inventado por los sobrevientas para vengarse.

Trasladando el concepto de Hugo Vezzetti (2003)elaborado para significar el Proceso a las Juntas militares en la Argentina en 1985, podemos decir que los juicios de Frankfurt constituyen una escena ${ }^{10}$, un punto de inflexión en la historia ya que condensa una trama histórica y, a la vez, se convierte en un núcleo duro y persistente sobre el cual vuelve el trabajo de la memoria. Es la culminación de todo un proceso, pero es, a su vez y, fundamentalmente, es un antecedentes de lo que vendrá después en materia de justicia retroactiva. Se trata de una escena a partir de la cual se abren nuevas narrativas, sentidos y se fundan nuevas memorias.

Aunque, los Juicios de Auschwitz en Frankfurt supusieron una importante ruptura con el pasado, en los años que le siguieron, el ímpetu de la Justicia en castigar estos crímenes mermó, considerablemente. Trabas legales, institucionales, materiales y políticas se combinaron para dificultar la tareas de los investigadores y fiscales ya que se necesitaban los testimonios de los escasos sobrevivientes; un gran número de los acusados se encontraban fuera de Alemania, por lo cual se requería cursar órdenes de extradición, citar a testigos residentes en el extranjero y demostrar los asesinatos cometidos a título individual. 
Con la caída del muro de Berlín y la posterior unificación de Alemania en 1990, se abrió, nuevamente, luego de tres décadas, un contexto favorable para continuar con la justicia. Una de las razones fue que con la nueva instancia política abierta en 1989 se pudo acceder a nuevos archivos, pero, además y sobre todo, la nueva Alemania buscó construir una identidad, democrática, pluralista y comprometida con los derechos humanos, profundizando la condena ética, moral y penal a la experiencia totalitaria del nacionalsocialismo. A partir de esa fecha, se produjo un vasto proceso de recuperación de la memoria, reparación histórica de las víctimas, construcción de museos y monumentos, que dieron, en cada caso, lugar a importantes debates en la sociedad entorno al hecho histórico-traumático. Desde el año 2005, una ley de República Alemana condena penalmente a todo aquel que niegue o minimice el Holocausto, medida que se extendió a varios países de Europa. Por otra parte, a principios de la década actual, la Oficina Central de Investigación de los Crímenes Nazis, anunció nuevos procesos a cuarenta guardias de Auschwitz por el delito de colaboración necesaria en la masacre del Tercer Reich, dando inicio a un nuevo intento en Alemania de juzgar a los responsables con vida de los crímenes cometidos durante el régimen nazi. De esta nueva etapa de rememoración o anamnesis, participa, notablemente, en el cine alemán, con una focalización en la crítica a la era de Adenauer, embarcada en el "boom económico", el conformismo y el intento de cerrar prontamente la página del pasado violento. En oposición, la filmografía hace una fuerte reivindicación de la figura del Fiscal General de Hesse, Fritz Bauer y su grupo de jóvenes colaboradores, verdaderos promotores de la rebelión contra la impunidad que se vivió en Alemania a fines los cincuenta y que tuvo como resultado la realización de los Juicios Auschwitz en Frankfurt. De la fuerte reactivación de la memoria en torno este acontecimiento y al Fiscal de Hesse, dan cuenta, además de Laberinto de mentiras, otros filmes alemanes de nuestra época como la película de Ilona Ziok, Fritz Bauer: muerte a plazos (2010), y Agenda Secreta (2015) de Lars Kraume.

\section{Notas}

1. Huyssen, Andreas (2002). En busca del futuro perdido. Cultura y memoria en tipos de globalización. México: Fondo de Cultura Económica, pp 13-22.

2. Como puede observarse en Pilar Calveiro,(1998)Poder y desaparición. Los Campos de concentración en la Argentina, Buenos Aires, Colihue y también en el documental cinematográfico, El Nuremberg argentino, de Miguel Rodriguez, estrenado en 2004.

3. Traverso, Enzo (2011). El pasado, instrucciones de uso. Buenos Aires: Prometeo, p. 53.

4. Giordano, R. (1987). Die Zweite Schuldoder Von der Last, Deutscherzu sein, Hamburg: Rasch \& Röhrig (La segunda culpa o la carga de ser alemán).

5. Müller, Ingo (2006). Los juristas del horror. Traducido por Carlos Armando Figueredo, Caracas, Venezuela, Editorial Actum. Pp. 322-405.

6. Los primeros juicios de Auschwitz fueron realizados en Cracovia, Polonia, en noviembre-diciembre de 1947.

7. Hay un documental anterior, Verdicton Auschwitz: The Frankfurt Auschwitz Trial 19631965, cuyo título original es Auschwitz vordem Frankfurter Schwurgericht, realizado en 1993, dirigido por Rolf Bickel y Dietrich Wagner. 
8. En la realidad, fueron tres fiscales jóvenes que actuaron con el apoyo del Fiscal General del Hesse, Dr. Fritz Bauer.

9. Feierstein, D. (2015). Juicios. Sobre la elaboración del genocidio II. Buenos Aires: Fondo de Cultura Económica, pp. 15-21.

10. Vezzetti, H. (2003). Pasado y Presente. Guerra, dictadura y sociedad en la Argentina. Buenos Aires: Siglo XXI, pp. 16-18.

\title{
Bibliografía
}

Feierstein, D. (2012). Memorias y representaciones. Sobre la elaboración del genocidio. Buenos Aires: Fondo de Cultura Económica. . (2015). Juicios. Sobre la elaboración del genocidio. Buenos Aires: Fondo de Cultura Económica.

Ferró, M. (1995). Historia contemporánea y cine. Barcelona: Ariel.

Huyssen, A. (2002). En busca del futuro perdido. Cultura y memoria en tipos de globalización. México: Fondo de Cultura Económica.

Müller, I. (2006). Los juristas del horror. Traducido por Carlos Armando Figueredo. Caracas, Venezuela: Editorial Actum.

Rosenstone, R. A. (1997). El pasado en imágenes. El desafío del cine a nuestra ideas de la historia. Barcelona: Ariel.

Traverso, E. (2011). El pasado, instrucciones de uso. Buenos Aires: Prometeo.

Vezzetti, H. (2003). Pasado y Presente. Guerra, dictadura y sociedad en la Argentina. Buenos Aires: Siglo XXI.

\begin{abstract}
One of the most remarkable features of the era of globalization is, without doubt, the central place that memory occupies in the culture and politics of Western societies. Indeed, since the last two decades of the 20th century, there has been an almost obsessive concern for the past and, particularly, for the memory of traumatic historical events. Such phenomenon can be attributed, among other explanations, to the fact that the global world, which emerged from the end of the Cold War, despite the optimistic first speculations, turned out to be a violent scenario, of genocides, ethnic, national and religious conflicts. In this way, the main protagonists of recent history were emigrants, refugees, genocide victims and perpetrators and, as Andreas Huyssen puts it, the Holocaust has become the universal interpretative matrix of the acts of mass violence (Huyssen, A., 2002, p. 13-22). On the other hand, and related to the above, there has been a renewed interest in memory and justice over the criminals of Nazism. In this process, the cinema has had a relevant role through a considerable number of fiction films and documentaries that took up, with assiduity the theme, from the $80 \mathrm{~s}$, a profusion that contrasts with the previous stage. According to our hypothesis, just as the Holocaust became a universal tropes in explaining the great massacres and genocides of the current era, the culture of globalization returned to the Shoah, formulating a strong criticism of the entire generation that followed the event
\end{abstract}


-main powers, political leaders, institutions- for sacrificing the past in terms of the present and the future and having enshrined oblivion, silence and impunity, for several decades. Within this context of revision of the National Socialist past and the concern for justice in relation to the perpetrators, of which the cinema plays a significant role, the present work will deal with the film Labyrinth de Lies (Giulio Ricciarelli, 2014), of its links with the historical context of production and the new meanings it builds around those traumatic events that took place at the middle of the previous century. Our approach considers the cinema as a source of history, in the sense that it gives an account of the historical context in which it arises, its concerns, its discourses (Ferró, Marc, 1995) and, on the other hand, it aims at the analysis of its representations to stop at the new senses that attributes to that past (Rosenstone, R., 1997).

Keywords: globalization - memory - Holocaust - justice - cinema.

Resumo: Uma das características mais notáveis no tempo da globalização é, sem dúvida, o lugar central que ocupa a memória na cultura e nas políticas das sociedades ocidentais. Realmente, a partir das últimas duas décadas do século de XX surgiu um quase obsessivo interesse pelo passado e, particularmente, para a memória dos fatos históricos traumáticos. Esse fenômeno pode ser atribuído, entre outras explicações, a que o mundo global, surgido no fim da Guerra Fria, resultou um cenário violento, de genocídios, conflitos étnicos, nacionais e religiosos. Deste modo, os personagens principais da história recente se tornaram emigrados, refugiados, genocidas, vítimas e vitimadores e, como analisa Andreas Huyssen, o Holocausto se converteu na matriz interpretativa universal dos fatos de violência massiva (Huyssen, 2002, p. 13-22). Por outro lado, e em relação com o anterior, surgiu um renovado interesse pela memória e a justiça sobre os criminais do nazismo. Neste processo, o cinema teve um importante papel através de um número considerável de filmes de ficção e documentais que retomaram assiduamente o tema, a partir da década dos 80 , profusão que contrasta com a etapa anterior.

Segunda nossa hipótese, assim como o Holocausto se tornou um tropo universal à hora de explicar os grandes massacres e genocídios da era atual, a cultura da globalização voltou à Shoá, fazendo uma crítica forte a toda a geração que seguiu o evento -potências, líderes políticos, instituições- por ter sacrificado o passado em função do presente e do futuro, e ter consagrado o olvido, o silêncio e a impunidade durante várias décadas.

Neste contexto de revisão do passado nacional-socialista e a preocupação pela justiça em relação com os perpetradores do qual participa notavelmente o cinema, este trabalho se ocupará do filme Labirinto de mentiras (Ricciarelli, 2014), dos seus vínculos com o contexto histórico de produção e os novos significados que constrói ao redor a aqueles fatos traumáticos que sucederam no século passado. Nosso enfoque considera ao cinema como fonte da história, no sentido que dá conta do contexto histórico no qual nasce, seus preocupações, seus discursos (Ferró, 1995), e, por outra parte, aponta à análise de suas representações para deter-se nos novos sentidos que atribui a esse passado (Rosenstone, 1997).

Palavras chave: globalização - memória - Holocausto - justiça - cinema. 